\title{
Uluslararası Antep-Halep Vakıfları Sempozyumu Bildirileri
}

Uluslararası Antep-Halep Vakıfları Sempozyumu Bildirileri, I-II-II, Sempozyum Koordinatörü: Yrd. Doç. Dr. İsmail Alttnöz, Gaziantep Üniversitesi-Gaziantep Üniversitesi Vakıflar Bölge Müdürlüğü Yay., İstanbul 2014, Sayfa Sayısı: 862.

İsmail Altnöz*

Vakıf müessesi maddî bir karşılık beklemeden başkalarına yardım etmeyi kendisine ulvî ve fevkalâde bir görev addeden bir medeniyet düşüncesinin ürünüdür. Vakıflar yüzyıllardan beri İslam ülkelerinde büyük bir ehemmiyet kazanmış, sosyal ve ekonomik hayat üzerinde derin tesirler icra etmiş olan dînî ve hukûkî müesseselerdir. Daha sonraki i̇slâm devletlerinde de devam eden bu gelenek Selçuklu, Beylikler ve Osmanlı Devleti'nde de devam etmiştir. Türk-i̇slâm Devletlerinde mükemmel bir şekilde uygulama alanı bulan bu teşekkül çok güzel sosyal hizmetlerin gerçekleşmesine vesile olmuştur.

Uluslararası Antep-Halep Vakıfları Sempozyumu Bildirileri adlı bu kitap, 21-24 Aralık 2009 tarihleri arasında Gaziantep Üniversitesi, Başbakanlık Vakıflar Genel Müdürlüğü - Gaziantep Vakıflar Bölge Müdürlüğü, Halep Üniversitesi ve Halep Vakıflar Müdürlüğü İşbirliği ile düzenlenen Uluslararası Antep-Halep Vakıfları Sempozyumu neticesinde ortaya çıkmıştır.

Türkiye-Suriye arasındaki bölgelerarası işbirliğinin geliştirilmesi amacıyla başlatılan tarih, kültür, bilim, sanat, ticaret ve sanayi alanındaki gelişmelere katkıda bulunmak düşüncesiyle böyle bir çaIışma tertip edilmişti.

Birinci Dünya Savaşı́nın sonunda gâlip devletlerce 1918 yılında çizilen sınırlar Suriye ve Türkiye'yi birbirinden o kadar uzaklaştırdı ki, geçmişten günümüze Türk kültüründe hâlâ kullanılmakta olan "Halep oradaysa arşın burada" vb. deyimler kaldı.

Ancak, aradan 90 yıl geçtikten sonra aynı kültüre mensup insanların bu ayrılığı sona ermeye başla-

* Yrd. Doç. Dr., KSÜ Fen-Edebiyat Fakültesi Tarih Bölümü Öğretim Üyesi, altinoz@ksu.edu.tr, ialtinoz@hotmail.com dı. Burada her iki ülke halkının ve yönetimlerinin katkısı büyüktür. Ancak, ne yazık ki, son birkaç yıl içerisinde Suriye'de cereyan eden iç savaş tekrar bu iki toplumun birbirinden kopmasına neden oldu.

Büyük Selçuklulardan Osmanlılara ve oradan da Türkiye ve Suriye Arap Cumhuriyetleri dönemine gelinceye kadar devlet adamları, önemli şahsiyetler ve aileler ülkenin her tarafinda medreseler, imâretler, mektepler, yollar, köprüler, kervansaraylar ve hastaneler yaptırmışlar, bunların masraflarını karşılamak üzere de vakıflar kurmuşlardır. Toplumun ihtiyacı olan eğitim, sağlık, kültür, sanat ve imâr faaliyetlerinin tamamına yakını devletin kasasından hiçbir şekilde para harcamadan bu vakıflar yoluyla gerçekleştirilmekteydi.

Bölgede insan haklarından çevreye, eğitimden sağlığa varıncaya kadar yüzlerce vakıf kurulmuştur. Bunlara ilâve olarak hayvan haklarını korumak maksadıyla hayvan vakıfları kurulmuş olup, bunlara mimari yapıların sırtlarında yer alan kuş-saraylar güzel bir örnek teşkil etmektedir.

Böyle bir uluslararası sempozyumu gerçekleştirmekle Türkiye ve Suriye akademisi ve kurumları bölgenin ve bölgede yaşayan halkların ortak müesseselerinden olan Vakıf konusuna ilgilerini göstermişlerdir. İkinci bin yılın ilk 10 yılında Türkiye ile Suriye arasında geliştirilen iktisadi, sosyal, kültürel faaliyetler her iki ülkenin gelişmesine büyük katkılar sağlamıştır.

Ancak etle trnak misali Antep ile Halep'in her anlamda tarih boyunca ayrılmaz bir bütün olduğu gerçeğinden hareketle, tarihin bize vermiş olduğu sorumlulukları yerine getirmek suretiyle geleceğe dönük ümitlerimizi koruyabiliriz. 
Ancak, tarihin ne garip cilvesidir ki; 2009 yılında gerçekleştirmiş olduğumuz bu Uuluslararası Antep-Halep Vakıfları Sempozyumu'nun bitiminden iki yıl sonra Suriye'de patlak veren iç karışıklık durumu bu tabloya gölge düşürmüştür. İki kardeş halk böylesine güzel bir firsat yakalamış iken, maalesef bu güzel tabloya kan ve gözyaşı damgasını vurmuştur. Özellikle Osmanlı döneminde Antep ve Halep'teki vakıf eserlerini konu alan bu sempozyum her iki şehirdeki vakıf eserlerinin bilim dünyasına tanıtımasına büyük katkı sağlamıştır. Ancak, Türkiye'nin hemen yanı başında cereyan eden bu savaş durumunun insanları perişan ettiği gibi Halep’teki diğer târihî yapılar ile birlikte vakıf eserlerini de perişan etmiştir.

Bu târihî eserler hakkında bilgilerin yer aldığı bu eser, tarihe bir not düşmenin yanında bir teselli kaynağı olarak kalacaktır. Üç cilt halinde basımı gerçekleştirilen bu çalışmanın birinci cildi Antep Vakıfları, ikinci cildi Halep Vakıfları, üçüncü cildi ise; bu iki şehrin vakıfları ile ilgili olarak yapılan Arapça çalışmaların Türkçe tercümelerinden oluşmaktadır. Bu kitaplar ile geleceğe miras olarak bırakılan vakıf eserler hakkındaki bilgiler konuya ilgisi olan kesimlere sunulmaktadır.

Savaşın diğer bir üzücü tarafi ise, 2009 yılında Antep ve Halep'te yapılan Uluslararası Antep-Halep Vakıfları Sempozyumu'na bilimsel metinleri sunan Suriyeli meslektaşlarımızın çoğunun akıbetlerinden haberdar olamayışımız bizi üzmektedir. Belki de bu meslektaşlarımızın bir kısmı savaş nedeniyle aramızdan ayrılarak ahirete irtihal eylemişlerdir. Bu meslektaşlarımızdan hayatını kaybedenlere Cenâb-ı Allah'tan rahmet, yakınlarına başsağlığı dileriz.

Üç cilt olarak yayımı gerçekleştirilen kitabın her cildinde Gaziantep Üniversitesi Rektörü Sayın Prof. Dr. M. Yavuz Coşkun'un Sunuş, Gaziantep Vakıflar Bölge Müdürü Sayın İsa Güven'in Takdim ve Sempozyum koordinatörü bendenizin Önsöz yazıları bulunmaktadır.

Yurtiçi ve yurtdışından toplam 120 bilim insanının katılımıyla gerçekleşen bu sempozyum kuşkusuz hem Türkiye hem de Suriye açısından faydalı olmuştur. En azından Antep ve Halep'teki vakıflar bu bilimsel eser sayesinde gelecek nesillere aktarılabilirse amacına ulaşmış olacaktır.

Eserin birinci cildinde Antep Vakıflarına yer verilmiştir. Bu ciltte yer alan bildiriler ise şu şekilde sıralanmaktadır: İsmail Altınöz, "Dulkadırlılardan Osmanlılara İntikal Eden Ayıntâb Vakıfları"; Bilgehan Pamuk, "Ayntâb Şehir Hayatında Vakıflar (XVI. Yüzyıl); Orlin Sabev, "Bulgaristan Arşivlerinde Saklanan Gaziantep ve Halep Vakıfları ile Illgili Osmanlı Belgeleri”; Mehmet Özkarcı, "Gaziantep Hanlarının Türk Mimarisindeki Yeri ve Önemi"; H. İnci Önal, "Vakıf Kütüphanelerinin Gaziantep Kültürüne ve Bilimsel Hayata Etkisi"; Alaattin Aköz, "XIX. Yüzyıl Antep Medrese Vakıfları"; Nuri Yavuz, "XVI. Yüzyılda Antep'te Eğitim ile İlgili Vakıf Müesseseleri”, Ali Yücel, “Osmanlı Su Kültürünün Bir Alt Başlığı Olarak Ayıntab’da Su Vakıfları'na Örnekler”; Oktay Karaman, “XVIII. ve XIX. Yüzyılarda Antep-Şehreküstü Mahallesinde Kurulan Vakıflar (Kurucularının Sosyo-Kültürel Özellikleri)"; İsmail Kıvrım, “Osmanlı Döneminde Antep’te Kadınların Kurduğu Vakıflar (XVII. Yüzyıldan Cumhuriyete)"; Zülfiye Koçak-Uysal Dıvrak, "Ayıntab'da Kurulan Kadın Vakıfları (1600-1800)"; Kenan Ziya Taş, "Vakıf Uygulamaları Çerçevesinde OsmanIı Döneminde (16. Yüzyıldan 20. Yüzyıl Başına) Halep ve Antep'teki Okullar"; Abdüllatif Armağan, “XVII. Yüzyıl Güneydoğu Anadolusu'nun Dinî-Sosyal Hayatından Bir Kesit: Antep Mevlevîhanesi"; Necla Günay, "Antep Mevlevîhanesi'nin Kuruluşu ve Mustafa Bin Yusuf Ağa Vakfiyesi"; Suzan Bayraktaroğlu, "Gaziantep Mevlevihanesi ve Vakıf Müzesi Olarak Değerlendirilmesi”, XIX. Yüzyılın İkinci Yarısında Antep'teki Vakıflar ve Gelirleri"; Ali Seyyar, "21. Yüzyılın Sosyal Sorunlarının Çözümünde Yerel STK'ların Yeni Rolleri: Gaziantep'teki Vakıfların Sosyal Politika Potansiyeli"; Özkan Yıldız, "Gaziantep'te Vakıf Hayatına Sosyolojik Bakış”; Naim Deniz, "Vakıfların Antep-Halep Ticari Hayatındaki Önemi"; Metin Kopar-Selim Hilmi Özkan, “Gaziantep'te Osmanlı Döneminde Kurulup Günümüzde Varlığını Devam Ettiren Vakıflar"; Nurettin Gemici, "Evliya Çelebi Seyahatnamesi'nde Ayıntab'ta Sosyo-Kültürel Hayat ve Vakıflar"; Adem Çalışkan, "Antep'te Sosyal Dayanışma Vakfina Güzel Bir Örnek: Gerciğinli-zâde el-hâc İbrahim Efendi Vakf"; i Ibrahim Etem Çakır, "Şeyh Fethullah Efendi Vakf". 
Kitabın ikinci cildinde Halep Vakıflarına yer verilmiştir. Bu ciltte yer alan bildiriler ise; şu şekilde yer almaktadır: Abdurrahman Acar-Mesut Ergin, “Halep'te Memlüklü Dönemine Ait Medrese Vakıfları"; Murat Alanoğlu, "Halep'te Kadın ve Kadın Vakıfları"; İsmail Yakıt, "Şair Nabi'nin Halep Vakıfları Hakkında Yazdığı Manzum Tarihlerin İncelenmesi”; Tahsin Özcan, “ibrahim Halebi'nin Mültekal'I-Ebhur Adlı Eserindeki Vakıf Hukuku ile İlgili Ahkam Üzerine Bir Değerlendirme"; M. Cemal Öztürk, "Arşiv Belgelerinde Halep Tekkeleri"; Güler Yarcı, "Halep Vilayeti'nde Ecnebi Vakıfları"; Şaban Ortak, "Halep'teki Müslüman Vakıflarına Yönelik Azınlık ve Yabancı Mahalleleri"; Mustafa Gencer, "Alman Okul Derneği'nin Antep ve Halep'teki Çalışmaları (1908-1918)"; Sultan Murat Topçu, “Köprülü Ailesinin Halep Vilayetindeki Vakıfları ve Günümüzdeki Durumları"; Hilmi Bayraktar, "Tanzimat'a Girerken Halep Sancağı Vakıfları Üzerine Bir Değerlendirme"; Alı Kılcı, "Osmanlı Dönemi Sonlarında Halep Vakıfları"; Ayten Ardel, "Osmanlı Arşiv Belgelerinde Halep Vakıfları"; Ayten Altıntaş, "Halep'de Bir Vakıf Hastane Ergün Kâmil Bimâristanı (1354)'nın Osmanlı Dönemi ve Akıl Hastaları İçin Önemi"; M. Vedat Gürbüz, "Osmanlı Toprak Yönetiminde Vakıflar ve Halep Vakıfları"; Ali Boran, "Halep Âdiliye (Dukakin-zâde Mehmet Paşa) Camisi Vakfiyesi ve Bugünkü Durumu”; Mustafa Öztürk, "1861-1865 Dönemi Halep Vakıflarının Muhasebesi"; Ercan Çağlayan, "Hicri 1289 (M. 1872) Tarihli 22277 Nolu Evkâf Defterine Göre Halep Sancağı'nda Bulunan Bazı Vakıflar ve Bunlara Bağlı Köy ve Mezraların Hâsılat Kayıtları”; Mehmet Kabacık, "177 Numaralı Evkâf Muhasebe Defterine Göre XIX. Yüzyıl Başlarında Halep Vakıfları"; Üçler Bulduk, "1584/85 Tarihli Halep Evkâf Defterine Göre Halep Vakıfları"; Kemal Özkurt, "Halep Altunboğa Camii"; Abdülmecid Şentürk, "Halep'te İbrahim Hanzâde (Sokullu) ve Sadrazam Şehlâ Ahmed Paşa Vakıfları́nın XIX. Yüzyılın Sonlarındaki Durumu”; Mustafa Güler, "XVIII. Asırda Halep Haremeyn Vakıfları"; Ayhan Doğan, "12230 Numaralı Halep Haremeyn Evkâfi Defteri Verileri Üzerine Bir Değerlendirme”; Kemal Gurulkan, "Halep'te Bulunan Haremeyn Evkâfi ve Surre"; Metin Akis, "1822 Halep Depremi Sonrasında Halep Vakıfla- rında Tamir Faaliyetleri”; Hasan Karaköse, "18. ve 19. Yüzyılda Halep'te Osmanlı Dönemi Sosyal ve Kültürel Hayatını Yansıtan Hasan Efendi Bin Ahmed Efendi Vakfiyesi (1206 (h)/1792 (m)".

Yukarıda adı geçen eserin üçüncü cildinde ise; bu iki şehrin vakıfları ile ilgili olarak yapılan Arapça çalışmaların Türkçe tercümelerinden oluşmaktadır. Bu ciltte yer alan bildiriler ise şu şekildedir: Abdulkadir Hatip-El-Hasenî, "Vakıf Sistemi, Geçmiş ve Günümüz Arasında Vakıf Kanunlarının Gelişimi"; Abdulkadir Muhammed Hüseyin, “Vakıfların Mezhepler Üzerindeki Etkisi: 'Örnek Olarak Halep Şehri'”; Abdülmun'im Zeynuddin, "Osmanlı Döneminde Halep'te Vakıfların Gelişimi: Dukagin Mehmed Paşa Vakıfları"; Adnan Mamo, "Bâb Bölgesindeki Osmanlı Vakıfları", Ahmed Kâtibî, "Ahmediye Medresesi"; Abdüsselam Râgıb, "Halep Şabaniye Medresesi"; Mahmud Fahurî, "Osmanlı Döneminden Günümüze Kadar Halepteki İslamî Vakıf Kütüphaneleri"; M. Lemya Câsir, "Halep'te Hüsreviyye Tekkesi Vakıfları"; Mahmud Mısrî, "Halep Vakıf Binalarının Yeniden Etkinleştirilmesi: Şerafiyye Medresesi Örneği"; Mahmud Akkêm, "Suriye'de Vakıflar İdaresi: Aktüel Problemler ve Islah Teklifleri"; Hasan Safiyüddin, "Halep Vakıf Kütüphanesi: Tarihi, Kaynakları ve Yeniden Candırılması"; Celaleddin Hancı, "Halep Şehrindeki Vakfedilmiş Astronomi Alet ve Enstrümanları Tarif-Niteleme ve Değerlendirme"; İbrahim Abdullah Salkınî, "Internet Ağında Vakfedilmiş Dijital Kütüphaneler ve Halepteki Vakıf Kütüphanelerinde Bundan Yararlanma İmkânları";

Antep-Halep Vakıflarını her yönüyle incelemeye tâbi tutan bu çalışma Suriye ve Türkiye'deki kardeşliğin pekişmesine yapmış olduğu kadar, her iki şehrin yakınlaşmasına ve kaynaşmasına da katkıda bulunmuştur. Özellikle et ve tırnak gibi birbirinden ayrılmayan Antep ve Halep şehirlerinde vakıfların iktisâdi faaliyetler açısından şehirlere ne tür canlılık kazandırdığı bu kitapta ele alınırken, vakıfların şehirleşmeye sağladığı katkılarda yine bu eserde yer almıştır. Vakıfların sosyal anlamda ictimâi faaliyetleri ise; yine bu kitapta özenle üzerinde durulan konular arasındadır. 
Birinci ciltte; Antep'in kadim medeniyetin mirasçıları olarak yer alan vakıfların şehir hayatına etkileri, bir ticaret merkezi olarak Gaziantep Vakıflarının ticareti canlandırma oynadığı rol, yine aynı şekilde bu vakıfların eğitim hayatına sağladığı faydalar üzerinde durulmuştur. Şehirlerin vazgeçilmez öğesi olan su ve su temini meselesi, yine adı geçen kitapta Ayıntâb Su Vakıflarına değinilerek vakfin burada önemine vurgu yapılmıştır. Ayrıca, Ayntâb şehrinde şehrin nüvesini oluşturan mahalle vakıflarına dikkat çekilmiş, özellikle bu şehirde kadınlar tarafindan kurulan "Kadın Vakıfları" ilgi odağı olmuştur. Antep şehrinde yer alan Antep Mevlevihânesi ve Vakıfları ile ilgili bol miktarda bu kitapta bildirinin yer alması ise, bu kitaba ayrı bir zenginlik katmıştır. Aynı zamanda geçmiş ile günümüz arasında köprü vazifesi gören vakıfların Antep şehrinde bir STK görevini görmesi, sosyal politika potansiyellerinin bulunması, vakıfların sosyolojik açıdan değerlendirilmesi, hatta sosyal ve kültürel hayatın zenginliği açısından Selçuklu, Dulkadır ve Osmanlı dönemindeki vakıfların büyük bir kısmının bugün de aynı şehirde hizmetlerine devam etmesi ise, sosyal şehircilik anlayışına güzel bir örnek teşkil etmektedir.

İkinci Ciltte; Vakıfların Halep şehrine iktisâdi, ictimâi, sosyal, kültürel anlamda yapmış olduğu katkılara değinilen bildirilerde Memlûk döneminden Osmanlıya intikal eden vakıflar, bu vakıfların şehrin kültürel hayata etkisi, özellikle şiir ve estetik konuları içeren bildiriler bu cildin önemli öğeleri arasında yer almaktadır. Halep'te yer alan tekke ve zaviyelerin faaliyetlerinin vakıflar sayesinde yürütüldüğüne dikkat çekilirken, bu şehirdeki ecnebi vakıfların da yer alması ilginçtir. Bunlara ilave olarak Halep şehrinin eşraf ve idarecileri tarafindan yapılan vakıfların şehrin imâr ve iskânında oynadığı rol kadar bunların özellikle imâr faaliyetlerinde oynadığı role dikkat çeken bildiriler de bu ciltte yer almaktadır. Devletin kasasından beş kuruş para harcanmadan sağlık hizmetlerin gerçekleştirildiği sağlık vakfiyeleri de Darüşşifalardan Bimaristan (akıl hastanesi)'a varıncaya kadar bu hizmetlerin vakıflar yoluyla gerçekleştirilmesi sosyal devlet örneğine güzel bir misal olarak bu kitapta yer almıştır. Bu cildin sonunda yer alan Haremeyn vakıfları da ecdânın Haremeyn bölgesine Osmanlı Coğrafyasının her tarafindan akârlar/gelirler yoluyla hizmet aktarılması da yine bu kitapta yer alan bildirilerde konu edilmektedir.

Üçüncü ciltte ise; Suriyeli bilim adamları tarafından Halep ile ilgili Arapça sunulan bildirilerin Türkçe tercümeleri yer almaktadır. Bu son ciltte; Halep'teki vakıf sisteminin geçmiş ile günümüz arasındaki bağlantılarına değinildikten sonra, Suriye'de Vakıf Kanunlarının gelişimine yaptı̆̆ katkılara dikkat çekilmektedir. Diğer taraftan ise; Halep'teki vakıfların mezhep üzerinde etkisine dikkat çeken bildiriler bulunmaktadır. Özellikle, Osmanlı döneminde Halep'in bir vakıf cenneti olduğunu gösteren bildirilerin Suriyeli bilim adamları tarafindan bu ciltte yer alması kitaba ayrı bir zenginlik katmaktadır. Bu şehirde yer alan vakıf kütüphaneleri ile birlikte, bu vakıflardan istifade edilerek aktüel problemlerin ıslah edilmesine dikkat çekilmiştir. Halep şehrindeki vakfedilmiş astronomi alet ve enstrümanlarının değerlendirilmesi, internet çağında vakfedilmiş dijital kütüphanelerin, geçmişteki bu vakıf medeniyetinden yararlanma imkânlarına değinilmesi, gerçekten geçmiştin günümüze bir köprü vazifesi görmüştür.

Netice itibariyle 2009 yılının aralık ayında iki gün Antep'te iki günde Halep'te gerçekleştirilen bu uluslararası sempozyum her iki toplumu birbirine yakınlaştırdığı gibi, devletler arasındaki iktisadî, ticari, sosyal, kültürel ve diplomasi arasındaki bağların da güçlenmesine katkıda bulunmuştu. Özellikle Antep ve Halep Üniversitelerinin bu alanda yaptkkları işbirlikleri bu sempozyum öncesinde ve sonrasında güzel şeylerin oluşmasına vesile olmuştu. Ancak, ne yazık ki, sempozyumun hemen ardından Suriye'de iç karışıklığın çıkması, bu işbirliğine gölge düşürmüş, kardeş ülkede kan ve gözyaşı hâkim olmuştur. Her iki ülkenin bilim adamlarının sunduğu bildirilerin dışında başka ülkelerden de katılan bilim adamlarınca sunulan bildiriler neticesinde adeta Antep ve Halep'in bir vakıf envanteri ortaya konulmaya çalışıımıştır. Sempozyumda sunulan bildirilen kitap haline getirilmesi ise, ayrı bir önem taşımaktadır. Şöyle ki; 
2009 yılında Halep şehrinde yer alan vakıf eserlerinin büyük bir kısmı savaş nedeniyle tahrip olmuş ve yıkılmıştr. Bugün virâneye dönen Halep şehrine ve vakıflara duyulan hasret daha da artmaktadır. Bu kitap bu özlemin giderilmesine bir nebzecikte olsa katkıda bulunabilirse, özellikle bugün Halep'te yıkıma uğrayan kadim vakıf medeniyetinin canlı şâhidi olarak gelecek nesillere bu bilgileri aktarabilirse kendimizi bahtiyar hissedeceğiz. Öncelikle bu kitapta yer alan Antep ve Halep Vakıflarının görsel malzemeleri tarihe tanıklık edecek bundan sonraki çalışmaları örneklik teşkil edebilirse amacına ulaşmış olacaktır. 